\title{
Erythrocyte selenium concentration predicts intensive care unit and hospital mortality in patients with septic shock: a prospective observational study
}

Nara Aline Costa ${ }^{1 *}$, Ana Lúcia Gut ${ }^{1}$, José Alexandre Coelho Pimentel², Silvia Maria Franciscato Cozzolino², Paula Schmidt Azevedo ${ }^{1}$, Ana Angélica Henrique Fernandes ${ }^{3}$, Bertha Furlan Polegato ${ }^{1}$, Suzana Erico Tanni ${ }^{1}$, Rafael Dezen Gaiolla', Leonardo Antonio Mamede Zornoff ${ }^{1}$, Sergio Alberto Rupp de Paiva ${ }^{1}$ and Marcos Ferreira Minicucci ${ }^{1}$

\begin{abstract}
Introduction: Selenoenzymes can modulate the extent of oxidative stress, which is recognized as a key feature of septic shock. The pathophysiologic role of erythrocyte selenium concentration in patients with septic shock remains unknown. Therefore, the objective of this study was to evaluate the association of erythrocyte selenium concentration with glutathione peroxidase (GPX1) activity, GPx1 polymorphisms and with ICU and hospital mortality in septic shock patients.
\end{abstract}

Methods: This prospective study included all patients older than 18 years with septic shock on admission or during their ICU stay, admitted to one of the three ICUs of our institution, from January to August 2012. At the time of the patients' enrollment, demographic information was recorded. Blood samples were taken within the first 72 hours of the patients' admission or within 72 hours of the septic shock diagnosis for determination of selenium status, protein carbonyl concentration, GPx1 activity and GPx1 Pro198Leu polymorphism (rs 1050450) genotyping.

Results: A total of 110 consecutive patients were evaluated. The mean age was $57.6 \pm 15.9$ years, $63.6 \%$ were male. Regarding selenium status, only erythrocyte selenium concentration was lower in patients who died in the ICU. The frequencies for GPx1 Pro198Leu polymorphism were 55\%, 38\% and 7\% for Pro/Pro, Pro/Leu and Leu/Leu, respectively. In the logistic regression models, erythrocyte selenium concentration was associated with ICU and hospital mortality in patients with septic shock even after adjustment for protein carbonyl concentration and acute physiology and chronic health evaluation II score (APACHE II) or sequential organ failure assessment (SOFA).

Conclusions: Erythrocyte selenium concentration was a predictor of ICU and hospital mortality in patients with septic shock. However, this effect was not due to GPx1 activity or Pro198Leu polymorphism.

\footnotetext{
* Correspondence: nac_nutri@hotmail.com

'Department of Internal Medicine, Botucatu Medical School, UNESP -

Universidade Estadual Paulista, Av. Prof. Montenegro s/n, Botucatu, São Paulo,

SP 18618970, Brazil

Full list of author information is available at the end of the article
} 


\section{Introduction}

Overall cellular oxidative burden is regulated by a balance between the rates of reactive oxygen species (ROS) generation and a variety of antioxidant enzymes/pathways. ROS are generally believed to be harmful because they cause oxidative damage to DNA, protein, lipids and other macromolecules. However, at nanomolar concentrations, these free radicals may play an important role in physiological processes, for example, by functioning as a second messenger in signal transduction pathways. Thus, ROS can be deleterious through modulation of signaling networks [1,2]. In addition, oxidative stress and mitochondrial dysfunction have been recognized as key features of severe sepsis and septic shock $[3,4]$. For this reason, in the last decade, antioxidant supplementation in critically ill patients has been evaluated [5,6]. Heyland et al. showed in a meta-analysis that antioxidants, particularly high-dose intravenous selenite, as monotherapy or in combination with other antioxidants, are a safe strategy and are associated with a trend toward reduction in outcomes, including mortality [5].

Selenium is an essential trace element, and its incorporation into selenoproteins is associated with biological functions. For instance, the increased glutathione peroxidase (GPx) activity is known to increase antioxidant defenses and reduce oxidative damage [7]. The finding of low plasma or whole blood selenium concentrations in critically ill patients has encouraged several selenium supplementation trials. Despite promising results, the optimal dose, method and time of administration remain to be established [8-11]. It is probable that the nutritional selenium status previous to intensive care unit (ICU) admission and specific patient characteristics could influence the response to selenium supplementation.

Usually, nutritional status of selenium is commonly assessed by direct measurement of plasma selenium concentration or indirectly by measuring the activity of the GPx [12]. However, studies that evaluated patients with systemic inflammatory response, plasma selenium concentration showed controversial results [13-15]. Heyland et al. in the REDOX study showed that baseline median plasma selenium levels were within normal limits in patients with multiple organ dysfunction [15]. In a study involving 91 critically ill patients, Stefanowicz et al. recently showed that plasma selenium is affected by the inflammatory response while erythrocyte selenium concentration is unaffected and can be used to reliably assess selenium status across a wide range of selenium intakes [12]. In addition, erythrocyte selenium concentrations reflect longer term nutritional status due to its incorporation in erythrocyte synthesis [16].

Eight GPx enzymes are expressed in humans, and several studies have demonstrated their association with health. Some GPxs (GPx1, GPx2, GPx3 and GPx4) are selenium- containing enzymes and, therefore, are implicated in different typical functions of selenoproteins, including inflammation, angiogenesis, and endothelial function [17]. However, the most studied action of GPxs is related to oxidative stress. Indeed, to protect against oxidative stress, GPxs work in a coordinated manner with other enzymatic antioxidants (superoxide dismutase, and catalase) to convert ROS to $\mathrm{H}_{2} \mathrm{O}$.

GPx1 is a selenoprotein that consists of four $22 \mathrm{kDa}$ subunits, each of which contains one atom of selenium. Some polymorphisms have been found in human GPx1, and Pro198Leu polymorphism is thought to be functional [18]. Despite the conflicting results, individuals carrying the variant alleles seem to have an altered response to selenium supplementation [19].

Therefore, the objective of this study was to evaluate the association of erythrocyte selenium concentration with GPx1 activity, Pro198Leu polymorphism and with both ICU and hospital mortality in septic shock patients.

\section{Materials and methods}

All procedures were approved by the Ethics Committee of Botucatu Medical School (4063/2011), and have therefore been performed in accordance with the ethical standards laid down in the 1964 Declaration of Helsinki and its later amendments. Written informed consent was obtained from all patients prior to their inclusion in the study. All patients older than 18 years with septic shock on admission or septic shock during their ICU stay who were admitted to one of the three 28-bed ICUs at our hospital between January and August 2012 were prospectively evaluated.

At the time of the patients' enrollment, demographic information, the acute physiology and chronic health evaluation (APACHE II) score and the sequential organ failure assessment (SOFA) score were recorded. Blood samples were taken within the first 72 hours of the patients' admission or within 72 hours after septic shock diagnosis for determination of selenium status, protein carbonyl concentration, GPx1 activity and Pro198Leu polymorphism genotyping.

Septic shock was defined as an infection-induced systemic inflammatory response with systolic blood pressure lower than $90 \mathrm{mmHg}$ or a mean arterial pressure lower than $70 \mathrm{mmHg}$ requiring the introduction of vasopressor drugs [20]. All patients were followed during their ICU and hospital stay. The ICU and hospital mortality were recorded.

\section{Laboratory analysis}

Total serum levels of sodium, potassium, magnesium, total calcium, phosphorus, C-reactive protein (CRP), albumin, creatinine and urea were measured using the dry chemistry method (Ortho Clinical Diagnostics VITROS 
950 ${ }^{\mathrm{max}}$; Johnson \& Johnson, New Brunswick, NJ, USA), and lactate was measured using Roche OMNI $S^{\text {Tw }}$ Blood Gas Analyzer (Roche Diagnostics, Basel, Switzerland). Hemograms were performed with a Coulter STKS hematology autoanalyzer (Coulter Electronics Ltd., Luton, Bedfordshire, UK).

\section{Protein carbonyl determination}

Measurement of protein carbonyl groups is the most widely utilized measure of protein oxidation [21]. Therefore, protein carbonyl levels were analyzed based on the reaction with dinitrophenylhydrazine $(\mathrm{DNPH})$ and the formation of a Schiff base according to the method described by Reznick and Packer [22].

\section{Selenium status and GPx1 activity}

Erythrocyte and plasma selenium concentrations were measured using hydride generation flame atomic absorption spectrometry as previously described $[19,23]$. The references for plasma selenium concentration were values between 1.07 to $1.27 \mu \mathrm{mol} / \mathrm{L}$ ( 84 to $100 \mu \mathrm{g} / \mathrm{L}$ ), and those for erythrocyte selenium concentration were values between 0.76 to $1.52 \mu \mathrm{mol} / \mathrm{L}$ (60 to $120 \mu \mathrm{g} / \mathrm{L}$ ) [24,25].

The glutathione peroxidase activity of red blood cell hemolysate was assessed using the method described by Paglia and Valentine using the Ransel kit (Randox Laboratories Ltd, Crumlin, County Antrim, UK) [26].

\section{Pro198Leu polymorphism}

The DNA was isolated from frozen blood samples with the illustra blood genomicPrep Mini Spin Kit (GE Healthcare, Waukesha, WI, USA). Polymerase chain reaction (PCR) primers based on the human GPx1 gene sequence flanking the 198 polymorphism (rs 1050450) (GPx1 forward primer, 50-TGCCCCTACGCAGGTAC A-30; GPx1 reverse primer, 50-TCCCAAATGACAAT GACACAG-30) were used to generate a 337-bp amplification product [24]. PCR was performed following a previously described method [27]. The analyses were performed in duplicate.

\section{Statistical analysis}

Data are expressed as the mean \pm standard deviation (SD) or the median (including the lower and upper quartiles). Comparisons between two groups for continuous variables were performed using Student's $t$ test and between three groups, one-way ANOVA for parameters with normal distribution. Comparisons between two groups for continuous variables were performed using MannWhitney test and between three groups, Kruskal-Wallis followed by Dunn's post hoc test for parameters with non-normal distribution. Fisher's test or the $\chi^{2}$ test was used for all categorical data. Spearman correlation was used to evaluate the association of continuous variables.
Logistic regression models were used to predict both ICU and hospital mortality in patients with septic shock. The primary outcome was ICU mortality, and the secondary outcome was hospital mortality. Erythrocyte selenium concentration was tested as a continuous independent variable. Parameters that exhibited significant difference in the univariate analysis were included as independent factors in logistic regression models. The only exceptions were variables with high collinearity among them (urea, albumin, and lactate). Data analysis was performed using SigmaPlot software for Windows v12.0 (Systat Software Inc., San Jose, CA, USA). $P$ values lower than 0.05 were considered statistically significant.

\section{Results}

One hundred and ten consecutive patients were evaluated. The mean age was $57.6 \pm 15.9$ years, $63.6 \%$ were male, the median ICU and hospital stays were 7 (3 to 13) and 13 (4 to 22 ) days, respectively. The mortality rate during the ICU stay was $54.5 \%$, and $63.6 \%$ died during hospital stay. The demographic, clinical and laboratory data are presented in Table 1. Patients who died during their ICU stay exhibit higher serum lactate, urea and protein carbonyl concentrations, as well as higher APACHE II and SOFA scores. These patients also exhibited lower serum albumin levels.

In our study, the erythrocyte GPx activity was 30.6 (24.0 to $38.4 \mathrm{U} / \mathrm{gHb})$. About $33.3 \%$ of the patients presented lower GPx activity than reference values (27.5 to $73.6 \mathrm{U} / \mathrm{gHb})$. However, GPx activity was not associated with mortality. Regarding selenium status, only erythrocyte selenium concentration was lower in septic patients who died in the ICU (Table 1). Importantly, both survivors and nonsurvivors had markedly low selenium concentration.

Our data showed a correlation between erythrocyte selenium levels and GPx $(\mathrm{r}=0.193 ; P=0.05)$, at the limit of statistic significance. On the other hand, there is no correlation between GPx and protein carbonyl values $(\mathrm{r}=-0.175 ; P=0.09)$ and erythrocyte selenium levels and protein carbonyl values $(\mathrm{r}=-0.153 ; P=0.133)$.

Genotype analysis was performed in 104 patients due to technical problems with the other samples. The genotype frequencies for GPx1 Pro198Leu polymorphism were 55\%, 38\% and 7\% for Pro/Pro, Pro/Leu and Leu/Leu, respectively. These frequencies are consistent with those expected under the Hardy-Weinberg equilibrium. The erythrocyte selenium concentration, GPx1 activity, protein carbonyl and mortality according to Pro198Leu polymorphism genotype are presented in Table 2. Only GP $\times 1$ activity was different between groups and higher in Leu/ Leu genotype. In addition, there was no association between GP×1 activity, erythrocyte selenium concentration and protein carbonyl when each genotype group was analyzed separately (Table 3 ). 
Table 1 Demographic, clinical and laboratory data of 110 patients with septic shock

\begin{tabular}{|c|c|c|c|}
\hline \multirow[t]{2}{*}{ Variable } & \multicolumn{2}{|l|}{ ICU mortality } & \multirow[t]{2}{*}{$P$ value } \\
\hline & Yes $(n=60)$ & No $(n=50)$ & \\
\hline Age, (years) & $58.8 \pm 15.7$ & $56.2 \pm 16.2$ & 0.395 \\
\hline Male, number (\%) & $36(60 \%)$ & $34(68 \%)$ & 0.503 \\
\hline SOFA score & $10.0(7.3-12.0)$ & $9.0(7.0-10.0)$ & 0.032 \\
\hline APACHE II score & $21.9 \pm 7.4$ & $17.7 \pm 6.7$ & 0.003 \\
\hline \multicolumn{4}{|l|}{ Sepsis focus, number (\%) } \\
\hline Respiratory & $34(57)$ & $27(54)$ & \multirow[t]{5}{*}{0.193} \\
\hline Soft tissue & $8(13)$ & $2(4)$ & \\
\hline Urinary & $4(7)$ & $7(14)$ & \\
\hline Abdominal & $12(20)$ & $9(18)$ & \\
\hline Others & $2(3)$ & $5(10)$ & \\
\hline MV, number (\%) & $58(97)$ & $38(76)$ & 0.003 \\
\hline RBC transfusion number (\%) & $37(62)$ & $28(56)$ & 0.684 \\
\hline Lactate, (mmol/L) & $2.2(1.3-3.8)$ & $1.6(1.1-2.2)$ & 0.007 \\
\hline Hemoglobin, (g/dl) & $10.9 \pm 2.3$ & $11.2 \pm 2.4$ & 0.534 \\
\hline Hematocrit, (\%) & $32.8 \pm 6.7$ & $33.8 \pm 7.2$ & 0.429 \\
\hline Leucocytes, $\left(10^{3} / \mathrm{mm}^{3}\right)$ & $16.1(10.6-21.1)$ & $12.7(9.2-17.5)$ & 0.070 \\
\hline Sodium, (mmol/L) & $142(137-147)$ & $140(137-146)$ & 0.286 \\
\hline Potassium, (mmol/L) & $4.2(3.8-4.7)$ & $4.1(3.6-4.8)$ & 0.631 \\
\hline Phosphorus, (mg/dl) & $4.4(3.4-5.4)$ & $3.7(2.8-4.6)$ & 0.073 \\
\hline Total calcium, (mg/dl) & $7.6(7.0-8.3)$ & $8.0(7.5-8.3)$ & 0.115 \\
\hline Magnesium, (mg/dl) & $2.1(1.8-2.3)$ & $1.9(1.7-2.2)$ & 0.180 \\
\hline Glycemia, (mg/dl) & $180(121-247)$ & $177(129-248)$ & 0.977 \\
\hline $\mathrm{CRP},(\mathrm{mg} / \mathrm{dl})$ & $23.0(8.0-31.5)$ & $23.0(6.5-36.0)$ & 0.511 \\
\hline Albumin, (g/dl) & $2.0(1.7-2.5)$ & $2.6(2.1-3.0)$ & 0.002 \\
\hline Urea, (mg/dl) & $96.5(52.3-138.5)$ & $54.5(42.0-92.5)$ & 0.004 \\
\hline Creatinine, (mg/dl) & $1.3(0.7-2.5)$ & $1.1(0.6-2.5)$ & 0.418 \\
\hline Erythrocyte Se, ( $\mu \mathrm{mol} / \mathrm{L})$ & $0.38 \pm 0.15$ & $0.46 \pm 0.14$ & 0.005 \\
\hline Plasma Se, $(\mu \mathrm{mol} / \mathrm{L})$ & $0.30 \pm 0.12$ & $0.29 \pm 0.11$ & 0.787 \\
\hline Protein carbonyl, (nmol/ml) & $14.6(5.2-26.1)$ & $5.4(3.4-21.0)$ & 0.021 \\
\hline GPx1, (U/g Hb) & $30.1(20.8-37.1)$ & $31.2(26.1-39.0)$ & 0.301 \\
\hline
\end{tabular}

Data are expressed as the mean \pm standard deviation (SD), median (including the lower and upper quartiles) or percentage. ICU, intensive care unit; SOFA, sequential organ failure assessment; APACHE II, acute physiology and chronic health evaluation II; MV, mechanical ventilation; RBC, red blood cell; CRP, C-reactive protein; Se, selenium concentration; GPx1, glutathione peroxidase activity.

Table 2 Erythrocyte selenium concentration, GPx1 activity, protein carbonyl and mortality according to Pro198Leu polymorphism genotype

\begin{tabular}{lllll}
\hline Variables & Pro/Pro $(\mathbf{n}=\mathbf{5 7})$ & Pro/Leu $(\mathbf{n}=\mathbf{4 0})$ & Leu/Leu $(\mathbf{n}=\mathbf{7})$ & \multicolumn{1}{c}{$\boldsymbol{P}$ value } \\
\hline Erythrocyte Se, $(\mu \mathrm{mol} / \mathrm{L})$ & $0.41 \pm 0.15$ & $0.42 \pm 0.14$ & $0.46 \pm 0.12$ & 0.655 \\
Protein carbonyl, $(\mathrm{nmol} / \mathrm{ml})$ & $13.5(4.6-24.2)$ & $7.5(4.4-25.7)$ & $5.3(3.1-17.5)$ & $35.9(24.7-51.5)$ \\
GPx1, (U/g Hb) & $28.5(19.8-36.7)$ & $31.1(27.7-41.0)$ & $9.1 \pm 1.9$ & 0.045 \\
SOFA score & $8.8 \pm 2.6$ & $10.4 \pm 4.3$ & $4(57)$ & 0.067 \\
ICU mortality, number (\%) & $27(47)$ & $26(65)$ & $5(71)$ & 0.227 \\
Hospital mortality, number (\%) & $31(54)$ & $30(75)$ & 0.105 \\
\hline
\end{tabular}

Data are expressed as the mean \pm standard deviation (SD), median (including the lower and upper quartiles) or percentage. GPx1, glutathione peroxidase activity; $\mathrm{Se}$, selenium concentration; SOFA, sequential organ failure assessment; ICU, intensive care unit. 
Table 3 Correlation among erythrocyte selenium concentration, GPx1 activity and protein carbonyl according to Pro198Leu polymorphism genotype

\begin{tabular}{|c|c|c|c|c|c|c|}
\hline & \multicolumn{2}{|l|}{ Pro/Pro } & \multicolumn{2}{|c|}{ Pro/Leu } & \multicolumn{2}{|c|}{ Leu/Leu } \\
\hline & \multicolumn{6}{|c|}{ Erythrocyte selenium concentration $(\mu \mathrm{g} / \mathrm{L})$} \\
\hline & $\bar{r}$ & $P$ & $r$ & $P$ & $r$ & $P$ \\
\hline GPx1, (U/g Hb) & 0.231 & 0.110 & 0.145 & 0.389 & 0.214 & 0.602 \\
\hline Protein carbonyl, $(\mathrm{nmol} / \mathrm{ml})$ & -0.219 & 0.121 & -0.080 & 0.650 & -0.179 & 0.660 \\
\hline
\end{tabular}

GPx1, glutathione peroxidase activity.

In the logistic regression models, the erythrocyte selenium concentration was associated with ICU and hospital mortality in patients with septic shock even after adjustment for protein carbonyl concentrations, SOFA or APACHE II scores (Table 4).

\section{Discussion}

The aim of this study was to evaluate the association of erythrocyte selenium concentration with GPx1 activity, Pro198Leu polymorphism and ICU and hospital mortality in septic shock patients. Erythrocyte selenium concentration was a predictor of mortality in these patients. However, this effect was not due to GPx1 activity or Pro198Leu polymorphism.

Septic shock is the major cause of death in the ICU, and despite increased knowledge of the pathogenesis of sepsis and the creation of 'bundles' of care by the international consortium 'Surviving Sepsis Campaign', the septic shock mortality rate remains high [28-30]. Oxidative stress plays an important role in the development of organ dysfunction and multiple organ failure in critically ill patients [4]. In our study, patients who died during the ICU stay exhibit higher protein carbonyl concentrations, a biomarker of protein oxidative damage [21]. These data reinforce the importance of oxidative stress in septic patients. For this reason, in the last decade, trials with trace elements and vitamin supplementation for critically ill patients have been performed. Among these micronutrients, selenium is particularly important, and despite promising results, further studies are needed to determine the optimal dose and best method and time of administration [5,6,31]. We believed that nutritional selenium status previous to ICU admission and $\mathrm{GP} \times 1$ Pro198Leu polymorphism could influence the response of selenium supplementation.
Selenium is an essential micronutrient that functions as a component of many selenoproteins in antioxidant and redox reactions. For instance, mortality in Keshan disease is considered to be related to a selenium deficiency associated with an oxidative aggression due to coxsackie infection leading to lethal cardiomyopathy [32]. Therefore, having a previous selenium deficiency could predispose to death patients suffering from septic shock [33].

More than 25 selenoprotein families have been identified, including glutathione peroxidases, phosphohydroxylglutathione peroxidase and thioredoxin reductases [7,34]. It is important to note that in these antioxidant enzymes, there is always one selenium atom, in the form of selenocysteine, at the active site required for its activity [35,36]. In healthy individuals, selenoprotein $\mathrm{P}$ is the major selenoprotein in plasma, accounting for $52 \%$ of the total plasma selenium. Glutathione peroxidase accounts for another $39 \%$, albumin for $9 \%$ and free selenium for less than $1 \%$ of total selenium [35].

Selenium status varies by country and corresponds to dietary selenium intake and dietary supplements. For instance, in the USA, 50\% of the population takes dietary supplements [37]. Therefore, it is difficult to compare plasmatic selenium levels between different studies. In critically ill patients, it is postulated that plasma selenium could be affected by the inflammatory response. However, in the REDOX trial, patients with sepsis presented the same amount of selenium as controls in the plasma [15]. Importantly, similar to our data, other studies showed that critical patients presented lower plasmatic selenium levels [38-40]. The reasons for these discrepancies remain to be elucidated.

Stefanowicz et al. showed recently in a noninflamed population a strong positive correlation between erythrocyte and plasma selenium concentration that was not

Table 4 Logistic regression models for ICU and hospital mortality in 110 patients with septic shock

\begin{tabular}{|c|c|c|c|c|c|c|}
\hline & \multicolumn{3}{|c|}{ ICU mortality } & \multicolumn{3}{|c|}{ Hospital mortality } \\
\hline & Odds ratio & $95 \% \mathrm{Cl}$ & $P$ value & Odds ratio & $95 \% \mathrm{Cl}$ & $P$ value \\
\hline Erythrocyte Se & 0.950 & $0.916-986$ & 0.007 & 0.955 & $0.920-0.992$ & 0.017 \\
\hline Erythrocyte Se* & 0.914 & $0.869-0.962$ & $<0.001$ & 0.927 & $0.883-0.973$ & 0.002 \\
\hline Erythrocyte Se** & 0.945 & $0.907-0.983$ & 0.006 & 0.950 & $0.912-0.989$ & 0.013 \\
\hline
\end{tabular}

${ }^{*}$ Adjusted by protein carbonyl concentration, and acute physiology and chronic health evaluation II (APACHE II); ${ }^{* *}$ adjusted by protein carbonyl concentration and sequential organ failure assessment (SOFA). ICU, intensive care unit; Se, selenium concentration. 
found in inflamed critically ill patients [12]. In addition, in these patients, plasma selenium was low and erythrocyte selenium concentration was normal. Their results suggest that plasma selenium is affected by the inflammatory response while erythrocyte selenium concentration is unaffected and can be used to reliably assess selenium status [12]. In our study, both survivors and nonsurvivors had low selenium concentration. Importantly, this low selenium concentration is in accord with the observed mortality. However, only erythrocyte selenium concentrations were associated with both ICU and hospital mortality in septic shock patients.

To investigate why erythrocyte selenium concentrations were associated with mortality in our patients, we also evaluated GPx1 activity and its Pro198Leu polymorphism. This polymorphism is associated with a cytidine-tothymidine substitution in exon 2 of the gene, promoting an amino acid change from proline to leucine at codon 198 [19]. Some studies revealed that the Leu allele is associated with lower responsiveness of the enzyme activity to selenium supplementation [41,42]. However, others did not observe this association [43]. In our study, GPx1 activity was higher in patients carrying the variant allele. However, we did not find any correlation between erythrocyte selenium concentration, GPx1 activity and protein carbonyl in the different genotypes. In addition, the different genotypes did not influence mortality in our patients.

It is important to note that there are other polymorphisms in the GPx gene that could also influence its activity, and these were not evaluated in this research. In addition, the association of thioredoxin reductase and selenoprotein $\mathrm{P}$ with erythrocyte selenium concentration was not previously evaluated in septic shock patients.

We should consider the limitations of this study. We only included patients from a single medical center. In addition, our sample size was relatively small. Finally, we did not measure whole blood selenium levels, only plasma and erythrocyte selenium concentration.

\section{Conclusions}

In conclusion, erythrocyte selenium concentration was a predictor of ICU and hospital mortality in patients with septic shock. However, this effect was not due to GPx1 activity or Pro198Leu polymorphism.

\section{Key messages}

- Erythrocyte selenium concentration is a predictor of ICU and hospital mortality in patients with septic shock.

- Erythrocyte selenium concentration effect as a predictor of mortality was not due to influence on GPx1 activity or Pro198Leu polymorphism.

\section{Abbreviations}

APACHE II: acute physiology and chronic health evaluation II score; CRP: C-reactive protein; GPx1: glutathione peroxidase 1; ICU: intensive care unit; PCR: polymerase chain reaction; ROS: reactive oxygen species;

SOFA: sequential organ failure assessment.

\section{Competing interests}

The authors declare that they have no competing interests.

\section{Authors' contributions}

JACP and SMFC carried out the molecular genetic studies and were involved in drafting the manuscript. ALG, PSA, BFP, AAHF and RDG participated in the acquisition and analysis of data, and were involved in drafting the manuscript. NAC participated in the acquisition and analysis of data, carried out the biochemical analysis and helped to draft the manuscript. SET performed the statistical analysis and critically revised the manuscript. LAMZ, SARP and MFM participated in the study design and coordination, helped to draft the manuscript, and critically revised it. All authors read and approved the final manuscript, and agree to be accountable for all aspects of the work.

\section{Acknowledgments}

This work was supported by CAPES ('Coordenação de Aperfeiçoamento de Pessoal de Nível Superior').

\section{Author details}

'Department of Internal Medicine, Botucatu Medical School, UNESP Universidade Estadual Paulista, Av. Prof. Montenegro s/n, Botucatu, São Paulo, SP 18618970, Brazil. ${ }^{2}$ Department of Food and Experimental Nutrition, Faculty of Pharmaceutical Science, University of São Paulo, Av. Prof. Almeida Prado, 1280, São Paulo, SP 05508-070, Brazil. ${ }^{3}$ Chemistry and Biochemistry Department, Institute of Biological Sciences, UNESP - Universidade Estadual Paulista, Av. Prof. Montenegro s/n, Botucatu, São Paulo, SP 18618970, Brazil.

Received: 31 December 2013 Accepted: 25 April 2014

Published: 7 May 2014

\section{References}

1. Lovat R, Preiser JC: Antioxidant therapy in intensive care. Curr Opin Crit Care 2003, 9:266-270.

2. Droge W: Free radicals in the physiological control of cell function. Physiol Rev 2002, 82:47-95.

3. Galley HF: Bench to bedside review: Targeting antioxidants to mitochondria in sepsis. Crit Care 2010, 14:230.

4. Motoyama T, Okamoto K, Kukita I, Hamaguchi M, Kinoshita Y, Ogawa H: Possible role of increased oxidant stress in multiple organ failure after systemic inflammatory response syndrome. Crit Care Med 2003, 31:1048-1052.

5. Heyland DK, Dhaliwal R, Suchner U, Berger MM: Antioxidants nutrients: a systematic review of trace elements and vitamins in the critically ill patient. Intensive Care Med 2005, 31:327-337.

6. Manzanares W, Dhaliwal R, Jiang X, Murch L, Heyland DK: Antioxidant micronutrients in the critically ill: a systematic review and meta-analysis. Crit Care 2012, 16:R66.

7. Kryukov GV, Castellano S, Novoselov SV, Lobanov AV, Zehtab O, Guigó R, Gladyshev VN: Characterization of mammalian selenoproteomes. Science 2003, 300:1439-1443.

8. Vincent IL, Forceville $X$ : Critically elucidating the role of selenium. Curr Opin Anesthesiol 2008, 21:148-154.

9. Alhazzani W, Jacobi J, Sindi A, Hartog C, Reinhart K, Kokkoris S, Gerlach H, Andrews P, Drabek T, Manzanares W, Cook DJ, Jaeschke RZ: The effect of selenium therapy on mortality in patients with sepsis syndrome: a systematic review and meta-analysis of randomized controlled trials. Crit Care Med 2013, 41:1555-1564.

10. Landucci F, Mancinelli P, De Gaudio AR, Virgili G: Selenium supplementation in critically ill patients: A systematic review and meta-analysis. J Crit Care 2014, 29:150-156.

11. Huang TS, Shyu YC, Chen HY, Lin LM, Lo CY, Yuan SS, Chen PJ: Effect of parenteral selenium supplementation in critically ill patients: a systematic review and meta-analysis. PLoS One 2013, 8:e54431.

12. Stefanowicz FA, Talwar D, O'Reilly DS, Dickinson N, Atkinson J, Hursthouse AS, Rankin J, Duncan A: Erythrocyte selenium concentration as a marker of selenium status. Clin Nutr 2013, 32:837-842. 
13. Duncan A, Talwar D, McMillan DC, Stefanowicz F, O'Reilly DS: Quantitative data on the magnitude of the systemic inflammatory response and its effect on micronutrient status based on plasma measurements. Am J Clin Nutr 2012, 95:64-71.

14. Nichol C, Herdman J, Sattar N, O'Dwyer PJ, St J, O'Reilly D, Littlejohn D, Fell G: Changes in the concentration of plasma selenium and selenoproteins after miner elective surgery: further evidence for the negative acute phase response. Clin Chem 1998, 44:1764-1766.

15. Heyland D, Muscedere J, Wischmeyer PE, Cook D, Jones G, Albert M, Elke G, Berger MM, Day AG: Canadian Critical Care Trials Group: a randomized trial of glutamine and antioxidants in critically ill patients. N Engl J Med 2013, 368:1489-1497.

16. Navarro-Alarcon M, Cabrera-Vique C: Selenium in food and the human body: a review. Sci Total Environ 2008, 400:115-141.

17. Polimanti R, Fuciarelli M, Destro-Bisol G, Battaggia C: Functional diversity of the glutathione peroxidase gene family among human populations: implications for genetic predisposition to disease and drug response. Pharmacogenomics 2013, 14:1037-1045.

18. Forsberg L, De Faire U, Morgenstern R: Low yield of polymorphisms from EST blast searching: analysis of genes related to oxidative stress and verification of the P197L polymorphism in GPx1. Hum Mutat 1999, 13:294-300

19. Cominetti C, Bortoli MC, Purgatto E, Ong TP, Moreno FS, Garrido AB Jr, Cozzolino SM: Associations between glutathione peroxidase-1 Pro198Leu polymorphism, selenium status, and DNA damage levels in obese women after consumption of Brazil nuts. Nutrition 2011, 27:891-896.

20. Dellinger RP, Levy MM, Carlet JM, Bion J, Parker MM, Jaeschke R, Reinhart K, Angus DC, Brun-Buisson C, Beale R, Calandra T, Dhainaut JF, Gerlach H, Harvey M, Marini JJ, Marshall J, Ranieri M, Ramsay G, Sevransky J, Thompson BT, Townsend S, Vender JS, Zimmerman JL, Vincent JL, International Surviving Sepsis Campaign Guidelines Committee; American Association of Critical-Care Nurses; American College of Chest Physicians; American College of Emergency Physicians; Canadian Critical Care Society; European Society of Clinical Microbiology and Infectious Diseases; European Society of Intensive Care Medicine; European Respiratory Society; International Sepsis Forum; Japanese Association for Acute Medicine; Japanese Society of Intensive Care Medicine; Society of Critical Care Medicine; Society of Hospital Medicine; Surgical Infection Society; World Federation of Societies of Intensive and Critical Care Medicine: Surviving sepsis campaign: international guidelines for management of severe sepsis and septic shock: 2008. Crit Care Med 2008, 36:296-327.

21. Dalle-Donne I, Rossi R, Giustarini D, Milzani A, Colombo R: Protein carbonyl groups as biomarkers of oxidative stress. Clin Chim Acta 2003, 329:23-38.

22. Reznick AZ, Packer L: Oxidative damage to proteins: spectrophotometric method for carbonyl assay. Methods Enzymol 1994, 233:357-363.

23. Correia PR, de Oliveira E, Oliveira PV: Simultaneous determination of manganese and selenium in serum by electrothermal atomic absorption spectrometry. Talanta 2002, 57:527-535.

24. Thomson CD: Assessment of requirements for selenium and adequacy of selenium status: a review. Eur J Clin Nutr 2004, 58:391-402.

25. Ortuño J, Ros G, Periago MJ, Martínez C, López G, Rodrigo J: [Nutritional importance of selenium]. Arch Latinoam Nutr 1997, 47:6-13.

26. Paglia DE, Valentine WN: Studies on quantitative and qualitative characterization of erythrocyte glutathione peroxidase. J Lab Clin Med 1967, 70:158-169.

27. Hu YJ, Li ZF, Diamond AM: Enhanced discrimination of single nucleotide polymorphism in genotyping by phosphorothioate proofreading allele-specific amplification. Anal Biochem 2007, 369:54-59.

28. Gerlach H, Keh D: Recent progress in sepsis epidemiology - have we learned enough? Crit Care 2003, 7:333-334.

29. Angus DC, van der Poll T: Severe sepsis and septic shock. N Engl J Med 2013, 369:840-851.

30. Dellinger RP, Levy MM, Rhodes A, Annane D, Gerlach H, Opal SM, Sevransky JE, Sprung CL, Douglas IS, Jaeschke R, Osborn TM, Nunnally ME, Townsend SR, Reinhart K, Kleinpell RM, Angus DC, Deutschman CS, Machado FR, Rubenfeld GD, Webb SA, Beale RJ, Vincent JL, Moreno R, Surviving Sepsis Campaign Guidelines Committee including the Pediatric Subgroup: Surviving sepsis campaign: international guidelines for management of severe sepsis and septic shock: 2012. Crit Care Med 2013, 41:580-637.

31. Heyland DK, Manzanares W: Pharmaconutrition with antioxidant micronutrients in the critically ill: The time has come! Nutrition 2013, 29:359-360.
32. Chen J: An original discovery: selenium deficiency and Keshan disease (an endemic heart disease). Asia Pac J Clin Nutr 2012, 21:320-326.

33. Andrews PJ, Avenell A, Noble DW, Campbell MK, Battison CG, Croal BL, Simpson WG, Norrie J, Vale LD, Cook J, de Verteuil R, Milne AC: Randomised trial of glutamine and selenium supplemented parenteral nutrition for critically ill patients. Protocol Version 9, 19 February 2007 known as SIGNET (Scottish Intensive care Glutamine or seleNium Evaluative Trial). Trials 2007, 8:25

34. Papp LV, Lu J, Holmgren A, Khanna KK: From selenium to selenoproteins: synthesis, identity, and their role in human health. Antioxid Redox Signal 2007, 9:775-806

35. Harrison I, Littlejohn D, Fell GS: Distribution of selenium in human blood plasma and serum. Analyst 1996, 121:189-194.

36. Forceville X: Effects of high doses of selenium, as sodium selenite, in septic shock patients a placebo-controlled, randomized, double-blind, multi-center phase II study-selenium and sepsis. J Trace Elem Med Biol 2007, 21:62-65.

37. Rayman MP: Selenium and human health. Lancet 2012, 379:1256-1268.

38. Hawker FH, Stewart PM, Snitch PJ: Effects of acute illness on selenium homeostasis. Crit Care Med 1990, 18:442-446.

39. Forceville X, Vitoux D, Gauzit R, Combes A, Lahilaire P, Chappuis P: Selenium, systemic immune response syndrome, sepsis, and outcome in critically ill patients. Crit Care Med 1998, 26:1536-1544.

40. Sakr Y, Reinhart K, Bloos F, Marx G, Russwurm S, Bauer M, Brunkhorst F: Time course and relationship between plasma selenium concentrations, systemic inflammatory response, sepsis, and multiorgan failure. $\mathrm{Br} J$ Anaesth 2007, 98:775-784.

41. Hu YJ, Diamond AM: Role of glutathione peroxidase 1 in breast cancer: loss of heterozygosity and allelic differences in the response to selenium. Cancer Res 2003, 63:3347-3351.

42. Lei C, Niu X, Wei J, Zhu J, Zhu Y: Interaction of glutathione peroxidase-1 and selenium in endemic dilated cardiomyopathy. Clin Chim Acta 2009, 399:102-108.

43. Jablonska E, Gromadzinska J, Reszka E, Wasowicz W, Sobala W, SzeszeniaDabrowska N, Boffetta P: Association between GPx1 Pro198Leu polymorphism, GPx1 activity and plasma selenium concentration in humans. Eur J Clin Nutr 2009, 48:383-386.

doi:10.1186/cc13860

Cite this article as: Costa et al:: Erythrocyte selenium concentration predicts intensive care unit and hospital mortality in patients with septic shock: a prospective observational study. Critical Care 2014 18:R92.

\section{Submit your next manuscript to BioMed Central and take full advantage of:}

- Convenient online submission

- Thorough peer review

- No space constraints or color figure charges

- Immediate publication on acceptance

- Inclusion in PubMed, CAS, Scopus and Google Scholar

- Research which is freely available for redistribution 